This item was submitted to Loughborough's Research Repository by the author.

Items in Figshare are protected by copyright, with all rights reserved, unless otherwise indicated.

\title{
A 'Diplomatic Republic of Europe’? Explaining role conceptions in EU foreign policy
}

PLEASE CITE THE PUBLISHED VERSION

http://dx.doi.org/10.1177/0010836714558638

PUBLISHER

(C) The Author(s). Published by SAGE

VERSION

AM (Accepted Manuscript)

\section{PUBLISHER STATEMENT}

This work is made available according to the conditions of the Creative Commons Attribution-NonCommercialNoDerivatives 4.0 International (CC BY-NC-ND 4.0) licence. Full details of this licence are available at: https://creativecommons.org/licenses/by-nc-nd/4.0/

\section{LICENCE}

CC BY-NC-ND 4.0

\section{REPOSITORY RECORD}

Chelotti, Nicola. 2019. "A 'diplomatic Republic of Europe'? Explaining Role Conceptions in EU Foreign Policy”. figshare. https://hdl.handle.net/2134/24080. 


\section{A 'Diplomatic Republic of Europe’? Explaining Role Conceptions in EU Foreign Policy}

The core function of a diplomat is to represent his/her sending state and advance its interests (article 3 of the Vienna Convention on Diplomatic Relations, 1961). Diplomats are sent abroad to establish relationships with other countries, gather information and write reports, and negotiate treaties that will benefit their country. They are in close contact with their home country's administration, and reproduce its beliefs and objectives. It is hardly surprising, then, that they tend to interpret their role in a strictly national way: diplomats are 'the sending state's face and soul in a receiving country or international organization’ (Faizullaerv, 2006: 501).

However, it may happen that, under certain circumstances, diplomats come to interpret their political role in a different way. For instance, a long stay in a host country may lead the diplomat to develop identification bonds with the host state/organization. The participation of national diplomats in the United Nations system has been hypothesized to positively affect their evaluation of that organization. And the context where these dynamics are more likely to occur is the European Union (EU): ideals are often invoked, identities constantly at stake, truly supranational/European attitudes possible. A growing number of studies have indeed come to analyse EU foreign policy in terms of socialization, learning and problem-solving. EU institutions are said not only to induce their participants into their procedural rules but also to instil supranational orientations - where diplomats are committed to designing and pursuing common European policies (among others, Howorth, 2010; 2012; Juncos and Pomorska, 2006; 
2011; Nuttall, 1992; M.E. Smith, 2000; Tonra, 2001). In other words, a 'diplomatic republic of Europe’ (Jørgensen, 1997) is emerging.

The aim of the article is twofold. First, using an original database of 138 questionnaires compiled by national diplomats participating in the committees of the Common Foreign and Security Policy (CFSP) and Common Security and Defence Policy (CSDP), it explores to what extent a diplomatic republic of Europe has really been formed or whether, vice versa, EU foreign policy is still seen through national lenses. More specifically, it investigates how national diplomats interpret their role when participating in CFSP/CSDP negotiations. Second, and more importantly, if the literature on socialization in EU foreign policy (more often than not) implicitly assumes that pro-European orientations are due to the contact with CFSP institutions, this article tests this assumption, and sets it against other non-EU-related variables (Beyers, 2005; Hooghe, 2005). Put in different terms, it examines the explanatory factors behind the adoption of diplomats' conceptions. In this vein, it also contributes to increasing our knowledge of EU decision-makers' orientations. In spite of its potential, the data that have been generated are scarce, and the field remains, overall, small (Beyers, 2010).

It is organized as follows. After briefly introducing the committee system in EU foreign policy, and offering a few methodological notes, a second section introduces the outcome variable of the research, and specifies how role conceptions are understood, operationalized and measured. A third section introduces the explanatory variables of the research: hypotheses drawn from EU socialization, institutionalism and intergovernmentalism are discussed. Next, these hypotheses are tested statistically and the results of the empirical analysis presented. A concluding section summarizes the findings and briefly discusses their implications for the study of EU foreign policy. 


\section{Committees in EU Foreign Policy}

Even after the changes brought about by the Treaty of Lisbon, the decision-making process of the CFSP/CSDP is centred on the Council of the EU (hereafter: Council) which represents the governments of member states. If, in the early Seventies, the European political cooperation was an arena where European heads of state and government and foreign ministers had 'fireside chats' about European and international politics, a network of national policy experts was soon created. Meetings between political directors and officials from national ministries became regular and frequent; issues of international politics were discussed in committees and parties, policies proposed and agreements reached (Nuttall, 1992). Over the years, the balance between ministers and national bureaucracy shifted in favour of the latter: EU foreign policy has been progressively elaborated by national diplomats, or bureaucratized, 'at the expense of popular will' (Bickerton, 2011: 185). It has been calculated that around two-thirds of the decisions in foreign and defence policy are taken without any involvement from ministers: supposing that $15-20$ per cent of the issues are agreed by senior bodies (Political and Security Committee, PSC and COREPER), lower-level working groups settle around a further 40-45 per cent of the issues on the agenda (Juncos and Pomorska, 2011).

Additionally, the frequency of the meetings of these committees led member states to assign the great majority of diplomats involved there to national departments (Permanent Representations, PRs) in Brussels. These diplomats, based in the PRs, having acquired a remarkable advantage, in terms of information, knowledge and experience, via-à-vis the officials in the capital, play a very relevant role in the 
formulation and negotiation of EU foreign policy: when negotiating, they do not always have a mandate from the capital, and one out of two feel they have sufficient leeway (XXXXXX2013). EU foreign policy is thus increasingly formulated, or Brusselized (Juncos and Pomorska, 2011), to a good extent, by national diplomats from Brussels. As a result, investigating their role conceptions is not only relevant for accumulating information on decision-makers' orientations, but can also suggest what forces guide, and give substance to, the CFSP/CSDP. If national officials in Brussels play a relevant role in its negotiation, and follow European perspectives, it may be the case that EU foreign policy amounts to more than the lowest common denominator of member states' diverging policy preferences, and aspires to be a more coherent political project.

To investigate diplomats' role conceptions, and their relative determinants, a closedended questionnaire was sent (April-July 2008) to all $^{1}$ the national officials participating in CFSP/CSDP committees: around 30 CFSP and CSDP working groups, the PSC, the EU Military Committee, the Nicolaidis group, etc. are the focus, and the population, of the research. The response rate was 36 per cent: 114 questionnaires were returned by mail, and another 24 were compiled online (for a total number of 138). Replies from 27 member states were registered.

\section{National and supranational role conceptions}

Role theory in International Relations has been applied to three different levels and traditions (Walker 1987): decision-making (the individual decision-maker is the unit of analysis), comparative foreign policy (the state is the unit of analysis); and structural 
theories (the basic structure of the international system is the unit of analysis). The role conceptions investigated in this article are situated at the micro, individual level. The focus is therefore on foreign policy-makers and on the images they hold concerning their (and their country's) role in international (European) affairs.

Human organizations may be defined as open systems of roles (Katz and Kahn, 1978). Within an organization, there are several organizational positions, each of which denotes a set of actions or expected behaviours (Ibidem: 188-189). Similarly, O’Sullivan et al. (1994: 270) define roles as 'socially defined positions and patterns of behaviour which are characterized by specific sets of rules, norms and expectations which serve to orientate and regulate the interaction, conduct and practices of individuals in social situations'. Roles delineate the context within which actors perceive themselves, the others, and perform their duties. As Biddle (1986: 68) clarifies, agreement seems to exist among role theorists that role refers to a triad of concepts: 'patterned and characteristic social behaviors, parts or identities that are assumed by social participants, and scripts or expectations for behavior that are understood by all and adhered to by performers'. 'Parts' indicate specific positions in an organization, whereas 'scripts' and 'expectations' specify the activities and attitudes attached to those parts ('roles'). 'Characteristic social behaviours' refer to the wider set of standards of behaviour related to a position or role.

When participating in CFSP/CSDP committees, national officials occupy a certain position or part (being a diplomat in the Council), to which themselves and others associate certain roles, as well as certain characteristic social behaviours. How individuals view themselves as diplomats is closely associated to the tasks they are expected to perform, how these expectations relate to their interpretation of the role, and the organizational and cultural features of the contexts they are embedded in. 
Perceptions of their own role are normative systems of self-reference that provide conceptions of reality, standards of assessment, feelings of allegiance to organized communities and generalised receipts for action (Mayntz, 1999; March and Olsen, 1995. In Marcussen and Trondal 2011: 596). As a result, they adopt certain conceptions or orientations of their role, and pose questions such as, 'what are the logics and practices of preparing the national position and conducting negotiations?', and 'what is the proper role I am expected to play in Council working groups?' (Beyers 2005: 902). Traditionally, the role these bureaucrats are expected to play in international negotiations, and in the Council, is national, or intergovernmental: they define themselves as national representatives, and are meant to maximize the national position. This happens for several reasons. First, defending the national interest is considered a key part of their job. Their 'principal' and 'employer' is the national government. Incentives, rewards and sanctions are found at this level. As a Czech official reported, "Yes, the European pressure is visible, and at times can be rather strong. But, at the end of the day, I'm a national diplomat: that is my job"2. When they negotiate, they do not do it on behalf of themselves, but of 'their Minister, their ministry, their government, their state'. When they negotiate, they 'are' the state (Neumann, 2005: 85). Secondly, diplomats grow up in national contexts, and develop basic political loyalties during adolescence, in relation to national institutions and myths. The EU intervenes only at a later stage in the personal and political formation of a diplomat, when the chances to considerably affect his/her beliefs are slim (Hooghe, 2005). Finally, an intergovernmental role conception is also reinforced by the features of the Council. The dominating image of the Council is one of 'hard bargaining' (Lewis, 1998): conflict is recurrent and determines the final result of the political process. Compared to other committees, Council committees are organized according to territory, and reproduce 
symbols that lead its participants to further enact their role as national delegates (Egeberg, 1999; Egeberg et al, 2003). All these elements are accentuated in foreign policy. Foreign policy is very close to the heart of state activities: in such a sensitive area, diplomats are supposed to advance national orientations in an even stronger way. The null expectation of this study can therefore be formulated as follows: 'National diplomats in EU foreign policy are expected to perceive themselves as advocates of the national interest, and adopt a national/intergovernmental role conception.'

On the other hand, it can be that these officials interpret, or come to interpret (see below), their role in a different way. It may be that instead of, or along with, ${ }^{3}$ a national conception, they assume a European or supranational orientation of their role - the CFSP/CSDP is understood as a political project where decisions are formed collectively with the objective of crafting a common European policy. National diplomats may consider themselves as a real 'diplomatic republic of Europe’ (Jørgensen, 1997): as a Slovenian official reported, 'Like me, the majority of diplomats participate in the group to strengthen the EU as a whole ... not as a collection of individual states' interests. ${ }^{4}$ The context itself of the Council is also said to be particularly conducive to the blurring of national and European orientations (Beyers, 2005; Lempp and Altenschmidt, 2007; Lewis, 1998, 2005). Shared norms - which include a culture of consensus, a friendly and cooperative atmosphere and the commitment to mutual responsibility - may lead to the formation of epistemic communities, where the policy sector is the most relevant point of reference, the national element fades away, and a strong sense of belonging to the group emerges. The literature about EU foreign and defence policy has revealed that national diplomats follow a series of group norms (constant consultation, confidentiality; consensus and domaines reserves, M.E. Smith 2000: 615-17) that facilitate cooperation and lead to the formation of an esprit de corps (Juncos and 
Pomorska, 2006: 6). There is a natural coordination reflex on almost every issue of international politics: national diplomats affirm that '[t]he question is now "what will our European partners say - what is the opinion in Europe?”' (Tonra, 2001: 261). The question that arises then is whether the compliance with the group's norms also leads to the redefinition of their diplomatic role, to expressing 'we feelings' and supranational role orientations. This is what the article now turns to investigate.

Operationalizing Role Conceptions

One of the major problems of the literature that has investigated EU diplomats' identities is that it 'remains so diverse in terms of conceptualization and operationalization of key variables that it is hard ... to draw conclusions about' the accumulation of knowledge on these topics (Beyers, 2010: 910. See also Hooghe, 2005: 873). The literature on EU foreign policy, for instance, does not always clearly differentiate between supranational orientations, esprit de corps and coordination reflexes - which are instead often lumped together as socialization. A more accurate research strategy that precisely defines intergovernmental and supranational role conceptions is therefore needed. Furthermore, these studies are mostly based on few and unsystematic interviews, memoirs and authorial insights.

This study builds on the research design of Beyers (2005), who analysed 13 working groups of the Economic Community (EC), and develops and adapts it to the CFSP/CSDP. Interviewees were asked to express, along a six-point ordinal scale - from 1 ('strongly disagree') to 6 ('strongly agree') - their points of view on the following six statements: ${ }^{5}$ 
1) 'In my opinion, in CFSP/CSDP committees we have to inform and defend our national position' (National Defence).

2) 'Information on national positions in CFSP/CSDP committees is useful in order to be able to take into account interests of the other member states when setting out our national policy'(National Information).

3) 'The unanimity rule and the veto member states have at their disposal are highly valuable features of the CFSP/CSDP' (Unanimity).

4) 'As far as EU foreign and security policy is concerned, goal of member states should be to promote and strengthen the role of the EU'(Strengthening the EU).

5) 'The main task of CFSP/CSDP committees is to look for common objectives and a common policy in collaboration with member states and EU institutions' (Common Objectives).

6) 'In CFSP/CSDP committees national officials at the EU level and EU institutions should play a major role in drawing up guidelines for national foreign policies' (Guidelines).

By conceptualizing and operationalizing the dependent variable in a way similar to Beyer's, the aim is to contribute to consolidating our knowledge on EU decisionmakers' attitudes. Two questions have thus been reproduced using the same wording, and other two have been very similarly phrased. ${ }^{6}$ In addition, two questions have been formulated with the objective of including more CFSP-specific aspects (e.g., the unanimity rule). It can also provide some elements for comparative purposes: it is widely recognized in the literature of the Council that socialization processes, 
negotiations, relevance of national interests vary across issues, sectors, and pillars.

The logic behind this (and Beyer's) operationalization is to unveil role conceptions through a set of indirect questions, rather than asking directly what institution they mostly identify with. In this way, the potential risks linked to the respondents' bias are minimised. The first three statements are thus constructed to suggest an intergovernmental role orientation, as can be inferred from the frequent repetitions of 'national', and from the inclusion of the unanimity rule, and of key expressions such as ‘defend our national position' and ‘setting out our national policy'. An intergovernmental (or national) role conception evokes an image of EU foreign policy as an arena where member states' interests are exchanged, balanced and defended. On the other hand, the last three propositions indicate a supranational role conception: attention is continuously paid to words such as 'common'; EU institutions are mentioned in the context of foreign policy; national diplomats should 'promote and strengthen the role of the EU', and 'play a major role in' the decision-making process. A supranational (or European) role conception interprets the EU and CFSP/CSDP as an autonomous level of policy-making promoting a common European project.

Do national officials adopt consistent and systematic interpretations of their role? To what extent are these six statements related? Do they eventually correspond to a supranational and/or intergovernmental conception? Is there a combination or a conflict of roles? In order to answer these questions, a confirmatory factor analysis is performed. Factor analysis is a multivariate technique which determines the number of underlying unobservable (latent) factors contained in a set of observed variables (the six statements), and categorizes these factors using their common aspects. 
Before presenting the results of the factorial analysis, a basic set of descriptive statistics is given in Table 1 . All of the six propositions received rather high scores, with the partial exception of Unanimity and Guidelines. In this sense, it can be observed that the most 'supranational' query (which attributed a leading role in EU foreign policy to Brussels actors) registered the lowest score; and that the value of 'Unanimity' - one of the key features of an intergovernmental reading of the CFSP/CSDP - is similarly relatively low. Whereas the other four propositions have values around five, these two propositions are below four.

[ТАВ.1]

In any case, the scores are sufficiently high for both supranational and intergovernmental statements - the weighted and composite mean being 4.33 and 4.55 , respectively, and the difference being small. These values are still basic observations of diplomats' role conceptions. Nonetheless, the fact that national delegates have assigned relatively high values to both dimensions is already a significant finding for the literature of EU foreign policy (much of which still interprets the CFSP as a largely intergovernmental and zero-sum game), as well as a first step towards rejecting the null expectation of the research. 
Factor analysis

The factor analysis aims to discover whether the six statements presented above can be explained in terms of a smaller number of variables ("factors"), and in particular of a supranational and intergovernmental role orientation. Running the analysis, two factors clearly emerge and are retained (oblique rotation, Promax): their eigenvalue (which measures the variance of each factor) is 1.12 and 1.04 - whereas the third factor has an eigenvalue of 0.07 . The pattern matrix confirms that these two factors correspond to the (supranational and intergovernmental) conceptions hypothesized above. The factor loadings calculate the strength of the association between each variable/statement and the two factors retained. The greater the strength, the greater the association to the latent factor. Items with a loading over 0.4 - which is considered a good indicator - are emphasized in bold. Table 2 reveals that those variables that aim to strengthen the EU's international role, look for common EU solutions and attribute to the EU level a greater role in formulating CFSP/CSDP guidelines are highly related to the first factor - they all convey an interpretation of diplomats' role as part of a group with European orientations. On the other hand, the factor loadings of 'National Defence', 'National Information' and 'Unanimity' - which suggests diplomats being advocates of the national interest exogenously defined - show high scores on the second factor.

[ТАB. 2]

National delegates thus adopt both role conceptions and not only an intergovernmental role playing - as a good part of the intergovernmental literature claims. There is no 
agreement among the scripts and expectations that are held by the various CFSP/CSDP diplomats. EU committees do not foster role consensus (Biddle 1986): the same position activates two different sets of roles and social behaviours. Many officials in fact interpret their role from a European perspective: the idea that the CFSP/CSDP is an autonomous level of policy-making with the objective of promoting a common European project is widely and systematically shared. This is quite remarkable, since it shows that a good number of delegates have shifted their political aspirations to the European level. However, the national role playing has certainly not disappeared, and the 'old' neofunctionalist expectation that all national officials would progressively lose their national loyalty appears, at best, naive.

Additionally, the correlation matrix does not confirm that national bureaucrats merge or oppose the two orientations. A high positive value would indicate that CFSP/CSDP diplomats naturally reconcile their national and European expectations, and their role would consist in delivering both at home and in Brussels (Lewis 2005). Conversely, a negative score would disclose an opposition between the two conceptions: those diplomats that score high on one dimension (supranationalism) would assign very low values to the intergovernmental items. They would appear subjected to conflicting pressures and incompatible expectations resulting in dissonance and role conflict (Lynch 2007). The interfactor correlation (0.017) is, instead, weak, and suggests that neither a positive combination nor a conflict of roles occurs. What is indicated, here, is a certain acquiescence in officials' political attitudes: they clearly and systematically adopt one role orientation, but at the same time neither combine nor reject the other. In more practical terms, it means that if they have attributed high scores (5-6) to the supranational statements, they have probably given moderate (around 3), not high or low, values to the intergovernmental ones. A closer examination of the pattern matrix 
and cross-loadings among the six variables confirms this reading, and reveals that in four cases ('National Defence'; 'National Information’; 'Common Objectives'; 'Guidelines'), forms of a more or less consistent positive combination of roles take place - although some conflicts ('Unanimity'; 'Strengthening the EU’) are also registered. The overall picture is one of unsystematic and weak correlations among variables and factors. $^{7}$

\section{Explanatory variables}

If CFSP/CSDP officials systematically interpret their role in an intergovernmental or supranational way, the reasons behind these interpretations are still unknown. How to explain this variance? Is it due to the experiences of the individual candidate; or to the characteristics of the country of origin? Or is it rather the different exposure to EU institutions? This section intends to deepen the analysis by investigating these dynamics. The explanatory variables of the research are presented in the rest of the section, and empirically tested in the next one.

\section{Socialization Hypotheses}

The first group of hypotheses concerns the experience of national diplomats inside EU institutions. The prolonged exposition to EU norms, the intense exchange of information, a high interaction between an increasing number of officials along several levels, are said to facilitate the development of trust, collegiality and allegiance to the 
EU. The literature on EU foreign policy that has investigated the socializing effects of the CFSP/CSDP (more or less implicitly) seems to assume that holding supranational role orientations is due to the contact with EU norms - although in fact the factors that explain that adoption are left largely unexamined.

Installing supranational norms is a gradual process. At the beginning, the relationship between old and new members is characterized by misunderstandings and miscommunication (Moreland and Levine, 2002). These spirals of uncertainty can be reduced and overcome through contact: contact is crucial to build trust in the group. As members acquire more information, uncertainty decreases, and newcomers become more adept in their roles. In other words, 'a more intense involvement of an individual ... lowers the social distance which strengthens the effectiveness of the socialization process and the ability of a collectivity to reproduce itself' (Beyers, 2010: 911).

Yet, as Beyers (2005: 911) observes, ‘contact', ‘interaction’ and ‘involvement’ are vague concepts, and should be better specified. They can refer to three different aspects: a) the length of the contact - that is, how long national diplomats have been participating in the decision-making process of the EU (H1: Length). One national official is reported to have said with regard to socialization to EU values: 'Of course, after some years your attitudes change’ (in Lempp and Altenschmidt, 2007: 10); b) the intensity of the contact, measured by the overall time spent working for their committee (H2: Intensity); and c) the density of diplomats' participation in the policy process - how frequently their committee(s) meet in Brussels (H3: Density). Socialization and an esprit de corps were more visible in the case of political directors and European correspondents since their meetings were the most frequent ones (Nuttall, 1992: 313). Most parties now meet once or twice per week; however, it depends on the case. For instance, in the first semester of 2011 the PSC met 57 times (averaging 2.2 meetings per week), the CIVCOM 45 times. 
On the other hand, Terrorism (International Aspects; 6 meetings) and Transatlantic Relations (COTRA, 10 meetings) are among the least institutionalized committees of the CFSP. This can have an impact on role conceptions. As a national representative affirmed, 'Because we meet in COTRA so rarely ... we do look at each other, but suspiciously, (...) you don’t even find the mood for cooperation' (Juncos and Pomorska, 2006: 6).

These three variables are operationalized by asking in the questionnaire, respectively, how many years they have been involved in the EU decision-making process; how much time they spend working on CFSP/CSDP tasks (on a five-point scale); and how many times they attend their CFSP/CSDP meetings (on a five-point scale). They are said to positively affect role conceptions: the greater the length, the intensity and density of the contact, the more likely the internalization of a supranational role conception will be.

Time is therefore measured only indirectly, through the number of years spent in contact with EU forums (also, Beyers, 2005). Panel designs through which representatives are interviewed before joining (t0), after spending some time (t1), and also after leaving EU institutions (t2), would certainly be promising, but are very complicated to implement on a large scale. However, one of the major problems that arise is that the quality of interaction may be lost: the relation between socialization and time is not necessarily linear. The marginal effect of each year may decrease: at first, newcomers are overwhelmed by a great deal of new information at one time about practices, procedures and rules of the group, which can lead to an identity crisis, and quick adoption of a new conception. The impact of new information 'may go pretty fast, much faster than often assumed’ (Beyers, 2010: 915). 
With this precautionary note in mind, one should also note that other trends may be operating. Liesbet Hooghe shows that senior Commission officials are generally more supranationally oriented than newcomers, and that the 'marginal effect of an additional year in the Commission is more or less linear with respect to time served' (2005: 877). The reason lies in the fact that at the beginning newcomers struggle to cope with all the new norms of the community. 'The prevailing attitude among newcomers appears to be to wait and see' (Hooghe, 2005: 878): understanding and being persuaded are two different processes, and passing from the former to the latter may require some time and/or participation in the group.

\section{Institutional Hypotheses}

Studies on socialization in the EU have in fact confirmed that officials interacting with the EU develop pro-European role orientations. However, what they find is that most of the time such an impact is weak and, more importantly, affected by factors that are not related to the EU (Quaglia et al., 2008). Individuals may support the norms of a group, but this is not necessarily because of socialization. From an institutional perspective, EU officials' roles are effectively shaped by institutional affiliations and experiences, but this endogeneity is embedded in multiple contexts. The European context is only one among several, and probably not even the most important, since a diplomat's identity is very likely to be formed mostly before arriving in Brussels, shaped by domestic (and also international) experiences. In this vein, socialization is conditional, and 'mediated through institutional political and cultural factors varying among the member states' and diplomats’ personal experiences (Beyers, 2005: 911) - which can combine with EU socialization, and facilitate or hinder the adoption of supranational 
role conceptions. As Hooghe (2005) concludes: several roads lead to supranational norms, but few through EU socialization.

In the following, some of these roads will be presented in more detail. They can be divided into two groups, the first referring to representatives' personal (and professional) experiences, and the second to the macro features of the country of origin. Spending a good part of the professional (and personal) life abroad (H4: International Career) may lead to a better knowledge and a more spontaneous acceptance of international contexts, and a decrease of the domestic influence. This in turn will induce national diplomats to more easily adapt to international (including European) norms. In contrast, a long national career (H5: Domestic Career) leads to the opposite expectation. Officials that worked (almost) exclusively in a national setting acquire an intense familiarity with domestic interests and habits. They will be more prone to replicate national insights. Both professional experiences are measured in number of years (obtained from the questionnaire). Furthermore, national representatives' orientations may also depend on their experience of their own state's departmental structure and coordination procedures (H6: Organizational Esteem). ${ }^{8}$ The expectation is that domestic deficiencies in delivering timely and high-quality policy products may lead national civil servants to consider a different (European) layer of governance as a more efficient, responsive and also legitimate source of political authority (Beyers, 2005).

The second group investigates variables at the level of the country of origin. One of these variables is the structure of the national polity (H7: Polity). Sharing competences is more easily accepted by those diplomats who are already embedded in a constitutional culture with multiple layers of authority. Hooghe (2005) finds that the best explanatory variable of Commission top officials' support for pro-Europe is federalism: a civil servant from Germany or Belgium is more likely to promote 
supranationalism than one who grew up in the United Kingdom or France. ${ }^{9}$ Additionally, since delegates are part of the national elite, in CFSP/CSDP committees they may replicate their values and beliefs, and adopt supranationalism because of elite's pro-integration bias. To measure these national orientations, two different indicators are used: first, the attitude of the national elite towards the CFSP/CSDP information provided by research conducted by the European Commission in 1996 (H8a: Elite). However, these data are only available for 15 countries. Second, to also include the countries of the 2004-07 enlargement, information on national public opinions' support towards the CFSP and CSDP (H8b: Public Opinion) are used (Eurobarometer surveys).

Finally, an intergovernmental reading of EU foreign policy suggests that while all states are generally reluctant to share their sovereignty in such a delicate sector, the most powerful ones are much more so (H9: Power). They can reach their goals in international politics independently, and thus have less interest in being tied by any international (European) constraint. Smaller (in terms of military capabilities) states can on the other hand have more incentives to co-operate (also integrate): taming big members, reducing power imbalances, also increasing their voice in international relations. Diplomats from smaller countries are therefore more likely to adopt a supranational role orientation, whereas officials from larger states will reject it. KoenigArchibugi (2004: 153-154) calculates member states’ military capabilities using the Composite Index of Material Capabilities (CIMC) developed by the Correlates of War Project. $^{10}$

The (nine) independent variables are summarized in Table 3. 


\section{Testing the Model}

The factor analysis has generated two new variables, based on the two factor scores, which are used in this section as outcome variables: ${ }^{11}$ first the results for the supranational role orientation are presented and next those for the intergovernmental one. The nine variables are tested through four different model specifications. A first useful strategy (Model 1) is to examine correlation coefficients and significance levels. Pearson product-moment correlation coefficients $(r)$ are used by Beyers (2005) to show the importance of domestic ties in explaining supranational role playing. The analysis is next strengthened through regression analyses. A linear regression (Model 2) tests the variables linked to socialization, and (Model 3) to the competitive, institutional hypotheses. Model 3 presents two versions (A and B). Since the data for Polity and Elite are only available for 15 countries, and a listwise approach has been used, the strategy adopted is to run a first regression with the explanatory variables for which data for all member states exist (EU Career; Seniority; Public opinion; Power), and then a second regression where Polity and Elite are added. Finally, all the variables are included to obtain Model 4. For the same reasons, two different regressions are also performed in this model.

\section{Supranational Role Conception}


Socialization. The analysis indicates that socialization is an important factor in explaining the adoption of a supranational role conception: the number of years spent in the EU decision-making process ('Length') is significant in all models (Table 4). The correlation coefficient is 0.30 ; this result suggests that the two variables are related and the strength of the relationship is moderate. Correlations, however, do not tell us why the two variables are correlated, and how steep the relationship is. This information is provided by the other models. Model 2 reveals that, assuming that all other variables are held constant, for every one year increase in Length, the supranational score is expected to increase by 0.092 - and the standardized regression coefficient $\beta$ is $0.30 .^{12}$ These values are confirmed when all the other variables are added: a one-year increase would yield a $0.083(\beta=0.29)$ and $0.109(\beta=0.40)$ unit increase in the predicted supranational score in Models 4A and 4B, respectively.

On the other hand, Intensity and Density have small values and are not significant in any of the models. One possible explanation lies in the population of the research - fulltimers based in national PRs. Almost 71 per cent of the interviewees devote more than 75 per cent of their working time to CFSP/CSDP dossiers. Furthermore, the vast majority of them (89 per cent) attend CFSP/CSDP meetings every week, often more than once a week (XXXXXX2014). In other words, their contact with EU institutions is generally both highly intense and dense: a greater variance in the interviewees' experiences would probably offer further indications on the explanatory power of these two variables. From a different angle, it could be argued that high intensity and density are conditions that corroborate the effects of a long permanence in EU institutions.

[ТАВ.4] 
Institutional Socialization. If the Length hypothesis has been confirmed, Table 4 also indicates that developing pro-European affiliations is part of a larger process of identity building, where what happens in Brussels is just one section of the story, and where different - not linked specifically to the EU - socializing contexts affect diplomats' role conception in any (including EU) negotiating setting. A previous long career abroad lessens the national predisposition and contributes to developing a more supranational orientation - although the strength of the relationship is rather modest $(r=0.19)$. International Career is also significant in Model 3 (in both versions): the standardized $\beta$ is 0.20 and 0.27 , respectively. However, when controlled for EU socialization, the relationship becomes substantially weaker and non-significant (Model 4). The individual experiences at the domestic level do not seem to have any impact: neither officials' domestic career nor the assessment of their own department(s) are related to a European role conception in any of the four models. The values are very modest and non-significant.

The impact of state-level variables, on the other hand, is substantial. In particular, participating in a decentralized decision-making process and the more pro-European attitudes of national public opinions appear to be significant factors. In the case of Polity, the correlation coefficient is 0.21 . In the two regression models, the value remains significant and strong: overall, among the nine explanatory variables, Polity is the variable that makes the largest unique contribution in the model - the standardized $\beta$ being 0.45 (in Model 3), which decreases to 0.35 when the socialization variables are included (Model 4). The more national decision-makers are embedded in a multilayered system, the more they are inclined to adopt a supranational role playing.

In addition, Public Opinion affects the way national diplomats perceive their role. A high degree of Europeism in a certain polity is positively associated with the 
supranationalism of their officials: $r$ is 0.23 , and the relationship holds significant and solid in the two regression analyses ( $\beta=0.30$ and 0.28 in Models 3 and 4, respectively). This shows again how role conceptions are formed in different contexts, and may depend on factors of different kinds, which respond to different (both individual- and macro-level) experiences. Somewhat surprisingly, ${ }^{13}$ Elite not only has little impact, but in Models 3 and 4 is negatively related to the outcome variable. However, the relationship is weak and non-significant. Finally, member states' military power is clearly a non-influential variable in any of the models: there is no evidence that diplomats from larger states oppose more strongly a common and supranational foreign policy, or that pro-European orientations are particularly shared among smaller countries' representatives.

\section{Intergovernmental Role Conception}

The same analysis has been replicated to explain the adoption of an intergovernmental role conception. The picture that emerges is remarkably different. While the nine variables of the research make a significant contribution in investigating pro-integration attitudes, the relationship between these variables and intergovernmentalism is weak and highly uncertain (Table 5). Overall, only three variables (Polity, Elite and Public Opinion) are correlated to the dependent variable, and none of them are significant in the five regressions. Analysing the table a bit more closely, the socialization variables do not appear to be relevant factors at all: neither the correlation nor the regressions confirm that diplomats newly arrived in Brussels assume a particularly intergovernmental orientation, or that a prolonged stay in Brussels leads to weak national role conceptions (Length). Similarly, Intensity and Density have a very limited 
impact, and their values also display rather counter-intuitive directions. In any case, all these scores are modest and non-significant.

Individual experiences also have equally very small, non-significant and ambiguous values. There is no correspondence, for instance, between a long career spent in the national administration, or a high esteem of the national policy-making, and a high intergovernmental score; and a wide international professional experience does not induce diplomats to disregard a national role playing.

Finally, two macro-level variables - the structure of the national polity and the degree of Europeism, with both proxies - are negatively correlated with an intergovernmental conception: the more decentralized the diplomats' country and the more pro-European the attitudes of either the elites and the public opinion of their state, the smaller the intergovernmental value of their orientation. The strength of the relationships is modest: $r$ is -0.23 for Polity, and -0.21 and -0.18 for Elite and Public Opinion, respectively. When controlled for other variables (Models 3 and 4), these values become smaller and non-significant - thus confirming that in the case of an intergovernmental conception, the connections are loose and inconsistent. Similar conclusions can be drawn when considering the Power variable: in these models military power is an extremely weak predictor: the realist expectation that diplomats from larger states are more likely to adopt national perspectives is thus rejected.

[ТАВ. 5]

\section{Conclusion}


Relying on a database of 138 questionnaires completed by national delegates to CFSP/CSDP committees, this article has investigated what role conceptions understood as expectations that guide behaviour - these diplomats adopt in those settings. The first remarkable finding is that they systematically assume supranational and intergovernmental orientations: while descriptive statistics reveal that diplomats assign relatively high scores to both supranational and intergovernmental statements, factor analysis has confirmed and strengthened this conclusion. In this sense, they partially form a truly diplomatic republic of Europe: although national insights remain present, aspirations of building a strong and common EU foreign policy are a key aspect of many diplomats' approach to the CFSP/CSDP. Diplomats' role conceptions (at the micro-level) can be linked here to national role conceptions (at the meso-level). On the one hand, they are certainly an important source of national (that is, member states') role conceptions. Policy-makers conceptions of their country's orientations, tasks and rules (towards EU foreign and defence policy, in this case), as well as their personality and political needs, combine with state characteristics (geopolitical location of a country; military, economic and technical resources; socio-economic demands as expressed through political parties; public opinion; national values, doctrines, ideologies; etc.) to give substance and shape to national role conceptions (Holsti 1970). On the other hand, CFSP/CSDP officials' orientations are associated to a supra-national (European) role conception - or, better, they can give indications of the existence (and robustness) of the preconditions of strong, reliable and consistent EU role conceptions (multilateralist, stabilizer, norm promoter, civilian or normative power, etc. See Elgström and Smith 2006).

The second part of the article deepens the analysis by testing some explanatory variables. A good number of national diplomats develop a supranational role playing; 
but is this due to their contact with EU institutions, as the literature on EU foreign policy has generally assumed and largely left unexplored? What emerges from the data is a complex and heterogeneous picture. In terms of role theory, it suggests how (national, European and international) institutions influence individual role conceptions and norms and expectations constrain behaviour; while at the same time these institutional pressures vary in intensity and success and are mediated through agency. In other words, in order to understand how roles are constructed, an institutional approach should be complemented by an interactional and an intentional perspective, which bring out agency and its involvement in defining roles (Aggestam 2006). More specifically, if a few variables are not related to the outcome variables, and several relationships are weak, ${ }^{14}$ some solid tendencies can be traced and some significant conclusions drawn. First, the socialization thesis is partially confirmed, and - unlike the EC and the Commission (Beyers, 2005; Hooghe, 2005) - EU socializing phenomena are registered in the CFSP/CSDP. This may in part confirm the distinctive nature of EU foreign policy' environment and cooperation. In particular, the number of years spent in the Council is a relatively strong explanatory variable of a supranational attitude. Intensity and Density have small and non-significant values. A possible explanation lies in the little variance in the experiences of the interviewees: since the population is full-time delegates to PRs, they generally spend much of their time on CFSP/CSDP issues, and often participate in Council meetings. Future research should develop more fine-grained designs to explore, inter alia, the channels of socialization: how is a supranational role conception transmitted, through what mechanisms and what actors (other national officials, EU institutions)? Time is still a disputed concept. This research has shown that the number of years - however crude and indirect an indicator it may be - is indeed a good predictor, and that if at the beginning diplomats are challenged with a lot of new 
information, this information needs some time to be accepted. However, the linearity of this link should be further investigated (Beyers, 2010). Linked to this, the relationship between the group and its members may change over time, and members can go through different phases, including divergence, eventual resocialization or even exit (Moreland and Levine, 2002).

Secondly, an intergovernmental perspective does not explain the development of role conceptions in Council committees. The factor analysis has rejected the null expectation of the research and shown that diplomats also interpret their role in supranational terms. A long domestic record does not affect role playing. ${ }^{15}$ What is more, the data of this research show very clearly that military power does not explain diplomats' attitudes. This is a remarkable finding: the expectations that representatives of larger member states are more likely to develop a national outlook or, vice versa, that delegates of smaller states assume a more pro-European orientation, are rejected in all the models tested.

Thirdly, the intuition that diplomats' conceptions are only marginally formed in EU contexts finds partial confirmation. If previous individual experiences do not significantly influence diplomats' orientations (with the partial exception of International Career), the structure of the national polity is a relatively strong predictor in both correlation and regression analyses: participating in a multilevel and decentralized decision-making system predisposes the delegate to more easily accept a pro-integration perspective. Finally, there is a certain correspondence between proEuropean attitudes of a certain polity and the role conceptions adopted by their representatives. This holds true for national public opinions more than for top decisionmakers. An explanation may reside in the - specifically national - nature of diplomatic elites’ activities. 
These findings can also offer useful indications on the decision-making system of the CFSP/CSDP. EU foreign policy is increasingly formulated by national officials in Brussels, with certain margins of discretion (XXXXXX2013). If many of them perceive their role - as this article has shown - in pro-European terms, it may be possible that EU foreign and defence policy comes to more than the lowest common denominator of member states' exogenously defined positions, and is (at least partially) formulated according to common, European insights. At minimum, it contributes to building a more constructive and less adversarial negotiating atmosphere, and will likely constrain overtly national approaches. However, some caveats may apply. First, the data offered here suggest that as many diplomats assume an intergovernmental script: intergovernmental elements coexist with supranationalism and similarly inform the CFSP/CSDP. Secondly, if Brussels diplomats play an important (sometimes major) part in EU foreign policy, the national level has certainly not disappeared and can be very effective in certain cases. Finally, CFSP/CSDP full-timers - even when enjoying a certain amount of leeway, and even when holding supranational orientations - may nonetheless still advance national perspectives in Council negotiations: pro-integration attitudes may belong to the personal sphere, but do not affect their public roles. It may also depend on the issue at hand and delegates' commitment to resolving it (Howorth, 2010). Future research should focus on these dynamics and investigate how and under what circumstances diplomats' supranational and intergovernmental role conceptions, the control of the domestic over the European level and the relative autonomy of the latter, and decision-making logics and styles, all interact and combine with each other to produce concrete EU foreign and defence policy outputs.

\footnotetext{
${ }^{1}$ There are two exceptions. For logistic reasons, only diplomats working full-time in PRs have been
} 
considered. Secondly, the Antici group and the ambassadors of COREPER II replied that their handling of CFSP/CSDP issues is very limited.

${ }^{2}$ Interview(14), Czech official, June 2008.

${ }^{3}$ The literature of socialization in the EU argues that, at minimum, supranational orientations are partially expressed (Egeberg, 1999; Egeberg et al., 2003; Hooghe, 2005). On the other hand, Lewis (2005) indicates that diplomats wear a 'Janus face': they perceive a dual loyalty, toward the state and the collective European project.

${ }^{4}$ Interview(15), Slovenian official, June 2008.

${ }^{5}$ One of the problems of interviews/questionnaires is social desirability bias - that is, the interviewees' tendency to select responses they consider more socially desirable. On the one hand, this research made use of self-administered questionnaires, which are generally believed to reduce this bias. On the other, interviewees are choosing between two orientations (pro-European versus pro-national) that can be said possessing a roughly similar degree of social acceptance.

${ }^{6}$ Statements n. 1 and n. 2 of this research exactly replicate Beyer's (2005: 919) questions n. 7 and n. 8, whereas statements n. 5 and n. 6 very closely resemble his questions n. 3 and n. 1.

${ }^{7}$ The results of this analysis are very similar, in their general lines, to what Beyers (2005) has found with regard to EC working groups: even in that study, the factor analysis suggested that officials consistently adopt two role conceptions (supranational and intergovernmental), and that a positive role combination did not occur. Some (weak) forms of conflict were found instead. A more accurate inspection of the matrices and factor loadings of the two studies - as well as a comparison of the two identical questions confirm that the domestic level and the national interest are a greater concern for foreign policy diplomats.

${ }^{8}$ Four different questions of the questionnaire - regarding the quality of the ministerial coordination; the quality of officials' training; the clearness; and detail of the instructions - have been combined through a factorial analysis to create an additional composite index. Only one factor has been retained (eigenvalue: 1.54), and all the factor loadings are above (+/-) 0.59. The relative factor scores are used as values of the independent variable.

${ }^{9}$ To operationalize this variable, the regional governance index prepared by Hooghe and Marks (2001) has been used. The reference year is 2000, and data cover only the then 15 members of the EU. This factor was therefore only tested for these countries. 
${ }^{10}$ The reference year is 2001, which corresponds to the latest available data when the analysis was first performed. Since the objective is to assess the power relationships among EU member states, the share of military power each state possesses in relation to the other EU countries rather than to all states in the international system is considered.

${ }^{11}$ Factor scores are the summary of the variation of the six statements for each official. They have been calculated through the regression method, based on promax rotated factors.

${ }^{12}$ Models 2, 3 and 4 (in Table 3 and 4) present only unstandardized regression coefficients. In order to allow a more immediate comparison of the effects of the independent variables on the dependent variables, standardized coefficients have been added to, and discussed in, the main text.

${ }^{13}$ Elite and Public Opinion are strongly correlated: their correlation coefficient is $0.73(\mathrm{p}<.001)$.

${ }^{14}$ In addition, other factors here not included (or self-selection or simply idiosyncratic elements) may play a relevant explanatory role. In this sense, it may be that national representatives develop supranational role playing simply because the EU is a political ideal which attracts their aspirations without much link with the experience they have in Brussels or elsewhere.

${ }^{15}$ There is little evidence that states rationally appoint to EU positions officials with an extensive domestic professional career. For more information on EU member states' strategies in selecting their diplomats, see XXXXXX2014. 


\section{Bibliography}

Aggestam L (2006) Role theory and European foreign policy: a framework of analysis. In Elgström O and Smith M (eds) The European Union's Roles in International Politics. Concepts and Analysis. London: Routledge, pp. 11-29.

Beyers J (2005) Multiple Embeddedness and Socialization in Europe: The Case of Council Officials. International Organization 59(4): 899-936.

Beyers J (2010) Conceptual and methodological challenges in the study of European socialization. Journal of European Public Policy 17(6): 909-920.

Bickerton C (2011) Towards a Social Theory of EU Foreign and Security Policy. Journal of Common Market Studies 49(1): 171-190.

Biddle BJ (1979) Role theory: Expectations, identities, and behaviors. New York: Academic Publishers.

Biddle BJ (1986) Recent Developments in Role Theory. American Review of Sociology 12: 67-92.

Egeberg M (1999) Transcending intergovernmentalism? Identity and role perceptions of national officials in EU decision-making. Journal of European Public Policy 6(3): 45674. 
Egeberg M, Schaefer G and Trondal J (2003) The Many Faces of EU Committee Governance. West European Politics 26(3): 19-40.

Elgström O and Smith M (eds) (2006) The European Union's Roles in International Politics. Concepts and Analysis. London: Routledge.

Faizullaev A (2006) Diplomacy and Self. Diplomacy and Statecraft 17(3): 497-522.

Holsti K (1970) National Role Conceptions in the Study of Foreign Policy. International Studies Quarterly 14(3): 233-309.

Hooghe L (2005) Several Roads Lead to International Norms, but Few Via International Socialization: A Case Study of the European Commission. International Organization 59(4): 861-898.

Hooghe L and Marks G (2001) Multi-level Governance and European Integration. Lanham, Md.: Rowman and Littlefield.

Howorth J (2010) The Political and Security Committee: a case study in ‘supranational inter-governmentalism’?. Cahiers Européens 1, http://www.cee.sciencespo.fr/fr/publications/les-cahiers-europeens.html. 
Howorth J (2012) Decision-making in security and defense policy: Towards supranational inter-governmentalism? Cooperation and Conflict 47(4): 433-453.

Jørgensen K (1997) PoCo: The Diplomatic Republic of Europe. In Jørgensen K (ed) Reflective Approaches to European Governance. Basingstoke: Palgrave Macmillan, pp.128-145.

Juncos A and Pomorska K (2006) Playing the Brussels game: Strategic socialization in the CFSP Council Working Groups. European Integration online Papers 10(11): http://eiop.or.at/eiop/texte/2006-011a.htm.

Juncos A and Pomorska K (2011) Invisible and unaccountable? National Representatives and Council Officials in EU foreign policy. Journal of European Public Policy 18(8): 1096-1114.

Katz D and Kahn RL (1978) The social psychology of organizations. New York: John Wiley \& Sons.

Koenig-Archibugi M (2004) Explaining Government Preferences for Institutional Change in EU Foreign and Security Policy. International Organization 57(1): 137-174.

Lempp J and Altenschmidt J (2007) Supranationalization through Socialization in the Council of the European Union. Paper presented at the UACES Annual Conference, Portsmouth, 3-5 September. 
Lewis J (1998) Is the "Hard Bargaining" Image of the Council Misleading? The Committee of Permanent Representatives and the Local Elections Directive. Journal of Common Market Studies 36(4): 479-504.

Lewis J (2005) The Janus Face of Brussels: Socialization and Everyday Decision Making in the European Union. International Organization 59(4): 937-971.

Lynch KD (2007) Modeling role enactment: Linking role theory and social cognition. Journal for the Theory of Social Behaviour 37(4): 379-399.

Marcussen M and Trondal J (2011) The OECD civil servant: Caught between Scylla and Charybdis. Review of International Political Economy 18(5): 592-621.

Moreland R and Levine J (2002) Socialization and Trust in Work Groups. Group Processes and Intergroup Relations 5(3): 185-201.

Neumann IB (2005) To Be a Diplomat. International Studies Perspectives 6(1): 72-93.

Nuttall S. (1992) European Political Cooperation. Oxford: Clarendon Press.

O’Sullivan T, Hartley J, Saunders D, Montgomery M, and Fiske J (1994) Key concepts in communication and cultural studies. London: Meuthen. 
Quaglia L, De Francesco F and Radaelli C (2008) Committee Governance and Socialization in the European Union. Journal of European Public Policy 15(1): 155166.

Smith ME (2000) Conforming to Europe: The Domestic Impact of Foreign Policy Cooperation. Journal of European Public Policy 7(4): 613-631.

Tonra B (2001) The Europeanisation of National Foreign Policy: Dutch, Danish and Irish Foreign Policy in the European Union. Aldershot: Ashgate.

Walker SG (1987) The Relevance of Role Theory to Foreign Policy Analysis. In Walker SG (ed) Role Theory and Foreign Policy Analysis. Durham: Duke University Press, pp. $1-4$. 